Animal Health Research Institute.

Assiut Laboratory.

\title{
Studies on cutaneous myiasis in sheep in Assiut Governorate
}

\author{
دراسات على التدويد الجلدى فى الاغنام بمحافظة أسيوط \\ By \\ Mohsen, I. Arafa \\ محســن إبراهيبــــم عرفـة \\ المـلخص العربـــــي

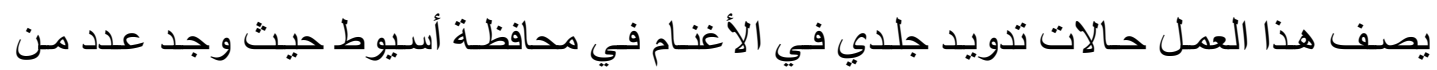

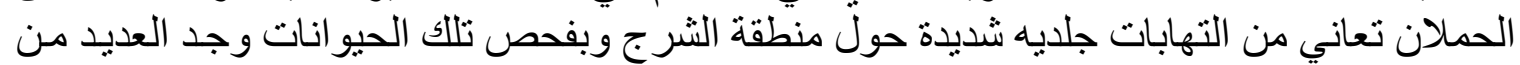

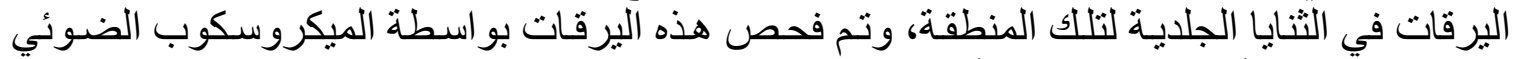

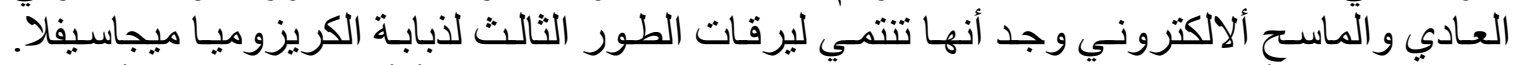

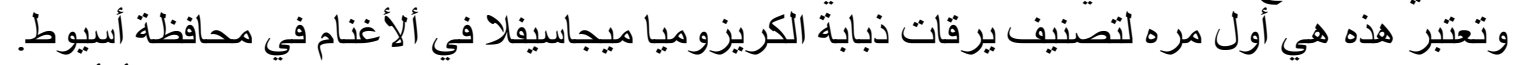

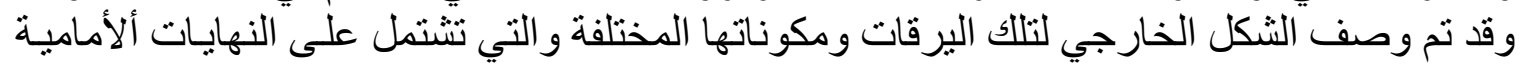

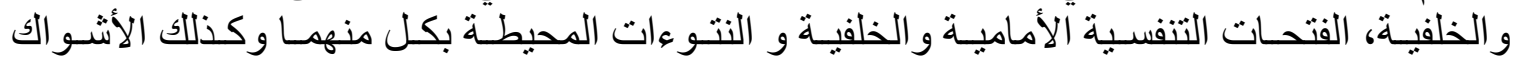 \\ الموجودة علي جسم اليرقة.

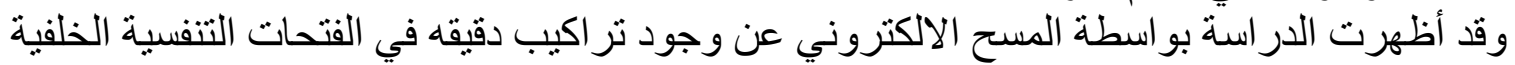

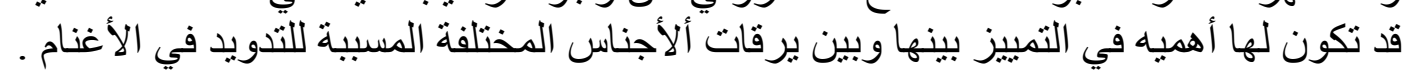

\section{Abstract}

Five lambs were obtained suffering from severe cutaneous perianal inflammatory lesions. Many larvae were detected between the folds of this region of diseased animals. Examination of these larvae with both light ordinary microscope and scan- electron microscope revealed that they are the third stage larvae of Chrysomia megacephala. This study is considered the first time of description of $C$. megacephala third stage larvae in sheep in Assiut Governorate. Different morphological features of the detected larvae were studied including anterior and posterior ends, anterior and posterior spiracles and arrangement of their papillae in addition to arrangement of the enter-segmental spines. Data which obtained by SEM about the posterior spiracles is considered of great important in helping of differentiation between myiatic larvae of sheep.

\section{Introduction}

Myiasis is the invasion of living tissues of animals and human with 
dipterous larvae, which at least for a certain period feed on the host $s$ dead or living tissues, liquid body substance or ingested food (Zumpt, 1965). Species of diptera causing myiasis may be obligatory, facultative or accidental (Hall \& Wall, 1995).

Myiasis is classified according to the parts of the body infected such as, cutaneous, urinogenital, ophthalmic, nasopharyngeal and intestinal (Service 1980). The life cycle of the species causing myiasis starts when female flies lay clusters of eggs in carcasses, wounds or soiled wool. Depending to the temperature larvae hatch from the eggs then begin to feed, grow rapidly (passing two ecdyses) becoming full grown maggots in about 2 - 19 days (Soulsby, 1982).

Myiasis may lead to the serious production losses in livestock industries (Humphrey, 1980) and in untreated infestation it may lead to death as a result of toxaemia, loss of skin or secondary bacterial infection (Blood et al., 1979)

In sheep, several forms of myiasis were detected but the commonest of them were the nasal myiasis caused by Oestrus ovis and wool myiasis caused by Lucilia and Chrysomyia sp. (Greenberg, 1971).

The application of scanning electron microscopy (SEM) techniques to study the insect ultra-structure has become very useful to observe the ultra-structural features of the larval instars which facilitate larval identification and differentiation (Sandeman et al., 1987, Aspoas, 1991, Meier, 1995, Khalifa \& Mowafy1997, Khedre, 1999 and Shaheen, et al., 2005).

The present work aimed to identification of the obtained larvae causing cutaneous myiasis in sheep in Assiut Governorate by both light and scanning electron microscopical examination.

\section{Materials and methods}

- The present materials were collected from five sheep (5-8 month old).These animals were suffering from cutaneous myiasis around the anal opening.

- Some of the collected larvae were prepared for whole mount after clearing in $10 \%$ potassium hydroxied (Morsy et al., 1991) and examined with light microscope and photomicrographed with the aid of Digital camera.

- Some of the freshly obtained larvae were put in $2.5 \%$ glutraldehyde and 
processed for scan- electron microscope and examined with JEOL- JSM 840A (Colwed \& O Cnnor, 2000).

- Larvae were identified according to keys provided by Greenberg (1971).

\section{$\underline{\text { Results }}$}

\section{Lesion in sheep}

Infected sheep were suffering from boil-like swellings at the perianal region containing several pouches filled with numerous larvae. Yellow secretion with offensive odour was oozing from the lesion.

On the basis of the morphological feature obtained by light and scanning microscope the encountered larvae were identified as those of Chrysomia megacephala.

\section{Gross examination:}

Detected larvae have cylindrical body with pointed anterior end while posterior end was wider. They were creamy white or grayish in color, and their dimensions were 6- $9 \mathrm{~mm}$ in length and their maximum width was $1.1-1.6 \mathrm{~mm}$.

\section{Light microscopical examination:}

Body of the detected larvae was composed of 12 segments separated from each other by a band of minute spines located at the margin of each segment (Plate I fig 1). These spines have strongly pigmented tips. Anterior spiracle is located on lateral side of second thoracic segment. It has fan - shaped finger like processes (AS) (Plate I fig 2).

Cephalopharygeal skeleton is wide, darkly pigmented and chitinzed at the anterior portions (Plate I fig 3), it is composed of:

- Two slightly curved retracted mouth hooks provided with pointed end.

The lower third of the hooks are often projected to the out side.

- A pair of accessory oral sclerites which are comma - shaped, slightly chitinized and it was faintly pigmented.

- A small rectangular hypostomal sclerite located just behind the mouth hook.

-Two horns of pharyngeal sclerites which were slightly chitinized. They 
were separated from each other by well demarcated middle incision. The dorsal horn has somewhat sharp end while the ventral one has rounded end.

- Ocular depression and slightly chitinized clypeal arch located between hypostome and pharyngeal sclerite.

The cephalic region of obtained larva is provided with two dome shaped anterior papillae (AP) (Plate I fig 3).

Anterior spiracle (AS) were located behind the dorsal horn of the pharyngeal sclerites, it is composed of digits - like bronchia arranged in a single fan-like row.

At the last body segment many separated pyramidal papillae were observed at the dorsal margin of this segment (PP) (Plate I fig 4).

\section{Scanning electron microscopical examination (S E M):}

S E M examination of third stage larvae of $C$. megacephala showed that:

1- The whole larva appeared with wrinkled tugment, it has tapering head which is clearly separated from other body segments and the maximum width of the larva is located near the middle of their body (plate 2 fig 1 ).

2 - The head (cephalic segment): It appeared as a small lobe projecting interiorly less in diameter than other parts of the body and its tegument is smooth. It is divided centrally into two parts by a shallow groove (plate 2 fig 2). On both sides of the apical part the antennal complex is found which is pyramidal in shape, composed of circular base and pointed tip (plate 2 fig 2 -3).

The oral ridges (labial lobe) are organized into two bands formed by cuticle scale like expansions. The cheeks are characterized by shallow fine striations directed laterally, while two openings from which the mouth hooks protruded are located just behind the apical part of the cephalic region (plate 2 fig 4).

3 - Anterior spiracles: They extend from both lateral sides of the second thoracic segment. Each one is composed of nine digits - like bronchia arranged in a single fan-like row (plate 2 fig 4). Higher magnification of the spiracle cleared that the upper end of each bronchia is rounded and provided with two elongated spiracular openings (plate 3 fig 1 ).

4- Spines: On the border of each body segment there are bands of small 
spines backwardly directed. Spine bands of the first thoracic segments are arranged in several rows as a collar-like. Spines of the first row are located singly provided with sharp end and swollen conical base. Double pointed spines were detected in other rows of thoracic spines (plate $3 \mathrm{fig} 2$ ). Spine bands of the abdominal segments are arranged in four interrupted rows their spines are triangular in shape, condensed, and finely pointed and they are larger in size than thoracic spines (plate 3 fig 3 ).

5- The caudal segment: The ventral aspect of the caudal segment shows the anal opening surrounded by two anal cerci laterally and five small papillae dorsally (plate 3 fig 4).

6- Posterior spiracles: Pair of posterior spiraclar discs are located in a shallow cavity at the dorsal aspect of the caudal segment. This cavity is surrounded by twelve cuticular papillae which are conical in shape. They are symmetrically arranged in two rings (two pairs dorsal, two pairs ventral and one on each lateral side) the inner ventral papillae are smallest one. Each spiraclar disc surrounded by thick opened oval peritreme provided with a barely visible button and it contains three converging slits unequal in length. Both sides of each peritreme is ornamented with eight transverse and oblique bands-like ligament and some bands located interiorly between the slits (plate 4 fig1, 2).

\section{Discussion}

Blow flies of genus Chrysomya are abundant in tropical and temperate areas of the world and have great importance from medical and sanitary standpoints. Chrysomia megacephala was originally recoded in Australia, the Oriental regions and South Africa (Zumpt,1965).

In Egypt, Gaber (1994) and Zohary (2002) succeeded to collect adult flies of $C$. megacephala from Suez and Sohag Provinces respectively. Therefore, this work is considered the first time for description of Chrysomia megacephala as third stage larvae a cause of cutaneous myiasis in sheep at Assiut Governorate .

Cutaneous myiasis caused by Chrysomya sp. was detected previously in two cases of humans in Iraq by Al- Rubiay (1998) and in animals by Greenberg \& Szyska (1984). 
Cutaneous lesions detected in the present work were seen at the perianal region of young animals; this may be related to that this site is mostly polluted by the feces especially in diarrheic lambs, hence attracting the blow flies for depositing their eggs.

Kettle (1984) mentioned that the common site of blow fly on sheep is the breech and tail where the wool has been fouled and remains moist by feces and urine. He also added that young sheep are more susceptible because of their tender skin.

Identification of the detected larvae depended on their morphological characters (Cephalopharygeal skeleton, anterior spiracles, bands of spines and posterior spiracles). These characters agree with the key organized by Hall and Smith (1993) where they mentioned that third stage larvae of Chrysomial species are characterized by:

- Larva is maggot-like, it has no head capsule and their mouth hooks are prominent.

- The body is provided with short and strong spines at the margin of each segment.

- Anterior spiracles terminating in a short finger- like rays.

- Posterior margin of segment (11) is provided with dorsal spines.

- The anal segment is provided with fleshy rosette- shaped protuberances.

- Tracheal trunks from posterior spiracles are without dark pigmentation.

- Posterior spiracles are visible, not recessed in a deep cavity surrounded with a ring of tubercles at the posterior face of the terminal segment. It is surrounded with open peritreme provided with three straight slits and indistinct button.

The differentiation between the present larva and other Chrysomia species depended on the following:

Light microscopical examination of cephalopharygeal skeleton of the detected larva showed that it is wide provided with two curved and pointed mouth hooks. Prins (1979) in a study of Chrysomia megacephala and Chrysomia chloropyga larvae observed that the buccal hooks of $C$. megacephala are widely 
convex with a slightly rounded angle on the upper basal surface while $C$. chloropyga has a flat dorsal surface and the upper basal surface is slightly increased in a more acute angle.

Accessory oral sclerite of the present larvae is comma - shaped. Ishijma (1967) and Prins (1982) mentionedl that presence of accessory oral sclerite is characteristic in some Chrysomia larvae where it was club - shaped in C. penguins, comma - shaped in C. megacephala and it not present in C. albiceps.

The present SEM illustrated that: The anterior spiracles of the present larva have 9 branchial papillae arranged in one row and their posterior spiracle has opened peritreme and barely visible button. This result agrees with that of Prins (1979), Greenberg \& Szyska (1984) and Khedre (1999) who mentioned that anterior spiracles of $C$. megacephala larvae has 8 -12 barnchiae, the peritrema is incomplete and their button is indistinguishable while these of $C$. albiceps has $11-12$ branhial papillae in the anterior spiracle and their posterior spiracles has open peritreme but no spiracular button.

The present study illustrated much more detailed ultra-structure in posterior spiracles (for the first time) the transverse and oblique bands which ornamented both sides of each peritreme. These bands might be related to gas regulation or preventing entry of waste substances across the respiratory system.

Thus it seems that it is of much importance to use SEM in identification of larval stages of myiasis - producing flies, more studies using light microscope and SEM should be undertaken on larvae obtained from domestic animals myiasis for identification of them.

\section{References}

Al- Rubiay, K. K. (1998): Human Cutaneous Myiasis: A report of two cases. Seience. B. V. 16: 223 - 226.

Aspoas, B.R. (1991): Comparative micromorphology of the third instar larvae and the breeding biology of some Afrotropical Sarcophaga (Diptera: Sarcophagidae) Med. Vet. Entomol. 5:437- 445

Blood, D. C., Henderson, J. A. and Radostits, O. M. (1979): Veterinary 
Medicine - A Text book of the Diseases of Cattle, Sheep, Pig, and Horses. Bailhere Tmdall, Landon.

Colwed, D. and O Cnnor, M. (2000): Scanning electron microscopy of Sarcophgid (Diptera) larvae recovered from a case of human cutaneous myiasis. J. Med. Entomol. , 37 (6) : 854- 859.

Gaber, R. M. R. (1994): Studies on the bionomics and medical importance of Chrysomya megacephala (Fabricius) (Diptera: Calliphoridae) in Egypt. M. Sc. Thesis, Faculty of Science. Cairo Univ.

Greenberg, B. (1971): Flies and Disease: Vol. (1) Ecology, Classification, and biotic associations. Princeton University Pres. Princeton New Jersey. 70: 455 - 462.

Greenberg, B. and Szyska, M. (1984): Immature stages and biology of fifteen species of preuian Calliphoridae (Diptera). Ann. Entomol. Soc. Am., 77:488- 517.

Hall, M. J. R. and Smith, K. G.V. (1993): Diptera causing myiasis in man. In (Medical Insects and Arachnids) Chapman and Hall, London. PP . 429- 469.

Hall, M. \& Wall, R. (1995): Myiasis of humans and domestic animals.Adv. Parasitol., 35: 257- 334.

Humphrey, J. D. (1980): Chrysomya bezziana : pathology of the old world screw worm fly infestations in cattle. Exp. Parasitol., 49: 381 - 397.

Ishijma, H. (1967): Revision of the third stage larvae of synantropic flies of Japan (Diptera: Anthomyidae, Muscidae, Calliphoridae and Sarcophagidae). Japan J. Sanit., 18: 47- 100.

Khalifa, R. M. A. and Mowafy, N. M. E. (1997): Light and scanning electron microscopical identification of a Sarcophagid larva causing intestinal myiasis. Egypt. J. Med. Sci. 18 (1) 235- 243.

Kettle, D. S. (1984): Medical and Veterinary Entomology. Crook Helm, London, United Kingdom.

Khedre, A. M.(1999): Comparative scanning electron microscopic study of Chrysmya megacephala (Fabricius) and Chrysmya albiceps (Wiedmann) Larvae (Diptera : Calliphordae).J. Egypt. Ger. Soc.Zool. 28: 203 - 216. 
Meier, R. (1995):Cladistic analysis of the Sepsidae (Cyclorrhapha: Diptera) based on a comparative scanning electron microscope study of larvae. Systematic Entomol.20:99-128.

Morsy, T.; Fayad, M.; Salama, M.; Sabry, A.; El_Serougi, A. and Abdallah, K. (1991): Some myiasis producers in Cairo and Giza abattoirs. J Egypt. Soc. Parasitol., 21: 339- 46.

Prins, A. (1979): Discovery of the oriental latrine fly Chrysomia megacephala (Fabricius) along the South-Western Coast of Africa. Ann. S. Afr. Mus. 78: 39 - 47.

Prins, A. (1982): Morphological and biological notes on six South African blowflies (Diptera, Calliphoridae) and their immature stages. Ann. S. Afr. Mus., 90: 201 - 217.

Sandeman, R. M., Collins, B. J. and Carnegie, P. R. (1987): A scanning electron microscope study of Lucilia caprina larvae and the development of blowfly strike in sheep. Inter. J. Parasitol.17: 759- 765.

Service, M. W. (1980): A guide to medical Entomology. MaCmillan press itd: pp $113-126$.

Shaheen, M. S., Hamza, A. I., and Abedel- Rahman, S. M. (2005):Light and scanning electron microscopy of the third- instar larva of Lucilia sericata (Diptera, Calliphoridae) recovered from a case of human intestinal myiasis. Assiut vet. Med. J. 51: 127- 140.

Soulsby, E. J. L. (1982): Helminthes, Arthropods and Protozoa of domestic animals. $7^{\text {th }} \mathrm{Ed}$, the English Book Society and Bailliere Tindall, London, U.K.

Zohary, N. M. (2002): Morphological and Experimental Studies on the Blowfly Chrysomia megacephala (Fabricius) (Diptera, Calliphoridae), in Egypt. M. Sc. Theis Faculty Science, Assiut Unive.

Zumpt, F. (1965): Myiasis in man and animals in old world. London, Butterworths 267pp. 
(Plate I) Light microscopic feature of Chrysomia megacephala $3^{\text {rd }}$ stage larvae:

(1) Third stage larva with tapering anterior end and broad posterior end.

(2) Lateral view of anterior end of the larva showing dark pigmented mouth hooks $(\mathrm{MH})$, accessory oral sclerite (OS) and fan shaped anterior spiracles (AS).

(3) Anterior end of C. megacephala third stage larva showing dome shape anterior papillae (AP).

(4) High magnification of the caudal end of the larva showing pyramidal shaped posterior papillae(PP). 
(Plate II) Scanning electron microscopy of Chrysomia megacephala $3^{\text {rd }}$ stage larvae:

(1) The whole larva appeared with wrinkled tugment.

(2) Cephalic segment showing smooth tegument divided centrally into two parts by a shallow groove, cuticular scales of the oral ridges (OR), the antennal complex (arrow) ,opening of the retracted mouth hooks (short arrow)and fine striations of the cheeks. (3) Higher magnification of the antennal complex which is formed of circular base, projecting from it a dorsally pointed pyramidal - shaped organelle.

(4) Anterior spiracles: at the lateral side of the second thoracic segment, composed from digits like bronchia arranged in a single fan- shaped row. Notes opening of the retracted mouth hooks (short arrow). 
(Plate III) Scanning electron microscopy of Chrysomia megacephala $3^{\text {rd }}$ stage larvae:

(1) Higher magnification of anterior spiracles showing the upper end of each bronchia provided with two elongated spiracular opening.

(2) Spine bands of the thoracic segments: characterized by singly pointed spines and few of double pointed spines (arrow).

(3) Spine bands of the abdominal segments which are finely pointed arranged in interrupted rows.

(4) Showing the anal opening(short arrow) surrounded by two anal cerci(ac)and five small papillae dorsally (arrow). 
(Plate VI) Scanning electron microscopy of Posterior spiracles of Chrysomia megacephala $3^{\text {rd }}$ stage larvae:

(1) Showing posterior spiracular discs located in a shallow cavity surrounded by 12 caudal papillae, each disc has thick opened peritreme, button (arrow) and three converging unequal slits.

(2) Showing eight transverse and oblique bands-like ligament on both sides of the peritreme. 
